\title{
Conclusion
}

In this book, we summarized important parts of our prior work targeted toward understanding the cognition of entrepreneurs. Specifically, our focus was on the role of knowledge, motivation, attention, identity, and emotions in the entrepreneurial process. Our work has several implications for scholars and practitioners interested in better understanding entrepreneurial cognition.

\section{Knowledge and Entrepreneurial Cognition}

In Chap. 2, we outlined the important role of knowledge for individuals' and teams' recognition of entrepreneurial opportunities. Specifically, we illustrated that individuals are heterogeneous in their knowledge endowments and that this heterogeneity explains, partly, why some recognize specific types of opportunities (e.g., commercial, sustainable, health-related, international) while others do not. We also found that knowledge sources internal and external to the entrepreneur can impact opportunity recognition. Finally, we explored the role of structural alignment as a cognitive process that interacts with prior knowledge in opportunity recognition. Our findings have important implications for scholarship and highlight future research possibilities.

First, entrepreneurship scholars who explore the connection between prior knowledge and opportunity identification should carefully differentiate between types of prior knowledge. For example, prior knowledge can 
lead individuals to identify more opportunities that are themselves more innovative, but some individuals may become entrenched in mental ruts as they gain more experience. This relationship could be curvilinear such that there is an early rise in the number and innovativeness of opportunities with increasing knowledge followed by a plateau and then a decline. These are just expectations, however; additional research is needed to fully understand these relationships. Moreover, it is likely that the relationship between prior knowledge and opportunity identification is more complicated than a clear-cut main-effect-only explanation. Through our analysis, we argued that the relationship between individuals' prior knowledge of customer problems and their ability to identify an opportunity varies depending on differences in the financial reward they receive for completing the task (Shepherd and DeTienne 2005; see also Csikszentmihalyi 1975, 2000; Maheswaran and Sternthal 1990). While it is valuable to explain why certain individuals (and not others) recognize opportunities based on their prior knowledge, the mechanisms underlying how prior knowledge facilitates opportunity identification remain largely unclear and warrant attention in future research.

Second, we found that entrepreneurial knowledge of the natural or communal environment influences individuals' recognition of opportunities for sustainable development. Specifically, individuals with these knowledge types are more likely than others to recognize opportunities based on changes in the natural and communal environment in which they live. Importantly, we also proposed that the impact these types of knowledge have on opportunity recognition is contingent on entrepreneurial knowledgethat is, knowledge of markets, ways to serve markets, and customer problems (Shane 2000). Specifically, there appears to be a complementary relationship between natural/communal environment knowledge and entrepreneurial knowledge, which implies that interactions between different knowledge types warrant particular attention in future research on the recognition of opportunities that go beyond generating financial gains for entrepreneurs. Interactions between knowledge types in opportunity recognition might also be central to extending businesses from developed economies into developing economies. For example, Hart (2006: 42) argued that "managers, particularly in multinational corporations, are more accustomed to viewing the global market as a single monolithic entity. They focus almost exclusively on the money economy and customers who have achieved a certain level of affluence." Hart (2006: 41) also described the consequences for the lack of economic development in developing countries: 
In the past, ignorance and isolation meant that those in the traditional and market economies were largely unaware of their plight. Today, however, the digital revolution is bringing information — and ideas - to growing number of the world's poor. Such knowledge is potentially empowering, as we will see, creating the potential to reform corrupt regimes, solve environmental problems, and spur more equitable forms of development.

Thus, Hart implied that knowledge about natural and communal problems may interact with knowledge about digital technologies when individuals recognize opportunities for sustainable development. We believe that future research can make important contributions by exploring this proposition. Further, since our theorizing was mainly focused on the formation of the belief that a sustainable development opportunity exists for someone (i.e., third-person opportunity), future research can also explore the role of knowledge about the natural and communal environment (and interactions with entrepreneurial knowledge) in forming the belief that a recognized opportunity can be exploited by the individual who recognized it (i.e., first-person opportunity belief) (McMullen and Shepherd 2006; Shepherd et al. 2007). Finally, it is important to note that little empirical work has tested the proposed (interaction) relationships between knowledge types and sustainable development opportunities. Such studies are urgently needed.

Third, we argued that prior knowledge of health-related problems derived from one's own health problems or the health problems of loved ones can trigger individuals' recognition of opportunities that improve the health of others. However, knowledge of health-related problems can be diverse and captures the medical reason behind the problem, interactions between parts of the problem (e.g., diagnosis, medication, cure plan), and/or the reasons current solutions are insufficient. Future research should go deeper and (potentially empirically) explore how types of health-related knowledge (perhaps interactively) impact opportunity identification. Further, the context of identifying opportunities based on prior knowledge of health-related problems may be interesting for studying the poorly understood phenomenon of user entrepreneurship (Shah and Tripsas 2007). Those who suffer from health-related problems and find insufficient solutions on the market may be particularly attentive to the adoption and improvement of existing products, potentially resulting in the identification of opportunities that not only improve their own health but others' health as well. It appears that future research investigating the user entrepreneurship process in the context of 
health-related technologies, products, and services can contribute to our understanding of opportunity identification and the role of knowledge therein. Finally, scholars may also investigate how people apply their technological knowledge to a health problem they have not experienced themselves. For example, based on their health-related knowledge, individuals could attend to health problems shared by people worldwide, or to the problems with the greatest financial market potential, or to the problems that are particularly prevalent in their own communities. Perhaps observing a healthrelated problem only through those suffering from it enables perspective taking in a more distant manner, which facilitates the creativity needed for recognizing health-related opportunities.

Fourth, in the context of international opportunities, Chap. 2 highlighted the importance of considering both internal and external knowledge sources to explain opportunity identification, particularly the contingent relationships between these knowledge sources. Specifically, it appears that entrepreneurs and their management teams with low levels of international knowledge capitalize most on external sources of international knowledge for opportunity recognition in foreign markets. This substitution effect is contrary to findings from absorptive capacity research, which emphasizes the need for knowledge in a particular domain in order to effectively incorporate additional knowledge in that domain (Cohen and Levinthal 1990; Zahra and George 2002). It is also contrary to findings by me (Holger) and my colleague (Domurath and Patzelt 2016), which showed that entrepreneurs who perceive that their venture has higher absorptive capacity for integrating knowledge about foreign markets are more likely to rely on foreign ties (as knowledge sources) when assessing the attractiveness of international opportunities for exploitation. Thus, the findings suggest the need for future research to explore the role of absorptive capacity in individuals' recognition of international opportunities. Further, it is interesting to note that venture capitalists can provide knowledge specific to internationalization to investees and that they seem to gain this knowledge from prior investees outside their domestic market. From an absorptive capacity perspective and related to the earlier discussion, one future research opportunity would be to explore how venture capital managers' own international experience and the experience their venture capital firm has gained through investments abroad interact in triggering future investees' internationalization. Chapter 2 also discussed the potentially important role of proximal firms with international knowledge, arguing that this knowledge might spill over to new ventures and thereby facilitate the recognition of opportunities in foreign markets. Indeed, this situation seems somewhat paradoxical because the most proximal firms 
trigger the recognition of opportunities in the most distant markets. However, research on knowledge spillover in the context of technological knowledge (Audretsch and Feldman 1996) helps resolve this paradox. It appears that there is further need to extend this notion of knowledge spillover beyond technological domains.

Finally, we elaborated on the role of cognitive processes, particularly the process of structural alignment, in translating entrepreneurial knowledge into the recognition of new business opportunities. While Baron (2006) and Baron and Ensley (2006) pointed out the importance of recognizing patterns for opportunity recognition, structural alignment is a particular cognitive process that describes how such patterns can be recognized. Given the central role of higher-order structural similarities in the process, our arguments explain why pattern recognition that guides opportunity identification is challenging (cf. Dutton 1993; Julian et al. 2008). Specifically, not only do entrepreneurs need to direct attention to environmental signals, but they also must invest cognitive energy to encode and process them at the deep level of structural relationships. It is here that entrepreneurs' prior knowledge comes into play because it facilitates the evaluation of structural relationships based on more developed mental representations of potential opportunities. In recognizing new opportunities, experienced entrepreneurs tend to focus on the causes and effects of difficulties in markets rather than on these markets' superficial features. As Chap. 2 illustrated, the role of knowledge in opportunity recognition goes beyond individuals' idiosyncratic advantages over others (Fiet 1996): prior knowledge serves as an important resource for superior cognitive processing that allows individuals to think of opportunities that have few superficial features in common with the original technology market. Finally, it is important to note that while there is initial evidence about structural-alignment processes in opportunity recognition, the setting of existing studies has been experimental and thus somewhat artificial. It is important that future studies explore, for example, the role of these processes in real-world conditions in terms of entrepreneurs' information overload, work stress, and the team environment typical of young ventures.

\section{Motivation and Entrepreneurial Cognition}

Both knowledge and motivation are critical for understanding opportunity beliefs and entrepreneurial action (McMullen and Shepherd 2006). In Chap. 3, we focused on the role of motivation in entrepreneurial cognition. 
First, we highlighted how motivation can direct attention toward identifying potential opportunities and toward exploiting those potential opportunities identified. We started this discussion with the promise of financial rewards. Financial rewards provide extrinsic motivation, which in turn enables individuals to generate a greater number of ideas, and these ideas tend to be more innovative. Further, this positive impact of financial rewards is even more positive when entrepreneurs have greater domain knowledge (Shepherd and DeTienne 2005).

Second, people can be passionate about various activities, and we described how individuals can be passionate about entrepreneurial activities, which drive effort, persistence, and hopefully eventual success for the key tasks of the entrepreneurial process. Further, there are different types of entrepreneurial passion. For example, Cardon et al. (2009) described that entrepreneurs can be passionate about innovating, founding, and/or developing a new venture. However, there is little research on how these different types of passion relate to and interact with other motivations. For example, to what extent can financial motivation compensate for the lack of certain types of passion in an entrepreneur's motivation to start or persist with a venture? However, perhaps financial motivation and different passion types are not substitutes but complements. For instance, perhaps an entrepreneur's motivation from passion for developing/growing a venture is even stronger when he or she is also financially motivated. It is important to address these and other questions to better understand the impact of (different types of) passion on entrepreneurs' motivations.

Third, we highlighted how fear of failure is often believed to obstruct entrepreneurial action given the uncertainty (and possibility of failure) inherent in the pursuit of potential opportunities. However, we highlighted the different dimensions of fear of failure and how some may motivate (rather than obstruct) entrepreneurial action. The dimensions of fear of failure are (1) fear of feeling shame and embarrassment, (2) fear of devaluing one's self-estimate, (3) fear of having an uncertain future, (4) fear of losing social influence, and (5) fear of upsetting important others (Conroy 2001; Conroy and Elliot 2004; Conroy et al. 2002). We also explained how passion and fear of failure can interact in determining entrepreneurial action. Again, from these different types of fear of failure, a number of novel research opportunities arise. For example, under what circumstances and for what types of ventures are these fear of failure dimensions most influential in deterring entrepreneurial action? Perhaps entrepreneurs who evaluate opportunities for ventures that will be highly 
visible in the media may be most influenced by their fear of shame and embarrassment and/or their fear of losing social influence, whereas entrepreneurs with weak personal financial resources might be most influenced by their fear of having an uncertain future when evaluating new business opportunities. Further, going forward, scholars can explore how different fear of failure dimensions interact with other motivational triggers for entrepreneurial action. For example, the impact of prosocial motivation on an entrepreneur's motivation to engage in social entrepreneurship may be diminished when the entrepreneur also has high fear of upsetting others. When a social venture fails, the numerous stakeholders of the venture-including those who are being helped-may become particularly upset, especially if they must return to the miserable situation they were in before the venture started to help them.

Fourth, in the chapter, we discussed how motivation can help explain the identification and exploitation of a special kind of potential opportunity-potential opportunities to preserve nature or sustain communities. We described how an individual's local environment can influence the way he or she "sees" the world, which in turn can motivate the identification and pursuit of potential opportunities to solve social or ecological problems. In exploiting these potential opportunities, entrepreneurs have the chance to generate economic gain for themselves and/or for others. This promise of economic gain for the self and/or others can also motivate the pursuit of potential opportunities for sustainable development (Patzelt and Shepherd 2011; Shepherd and Patzelt 2011). However, to date, we have little empirical evidence of how economic and non-economic gains motivate entrepreneurs' recognition and exploitation of opportunities for sustaining natural and communal environments.

Fifth, individuals are also embedded in environments that can experience or reflect negative health situations - their own or close others-and these experiences can motivate the identification and exploitation of potential opportunities to offer health-related solutions (Shepherd and Patzelt 2015). Moreover, many people with physical or psychological problems are drawn to entrepreneurial careers because these careers provide flexibility, autonomy, and performance-related advantages not available in employment (e.g., Wiklund et al. 2016). However, under what circumstances are those suffering with physical or psychological problems able to adjust their ventures to their needs and therefore maintain motivation over time? For example, some industries may be so dynamic that keeping up with competition requires adaptation that is so fast or has to occur in such a way that it is 
incompatible with the needs of entrepreneurs with health-related problems. Indeed, in such situations, the competitive pressure faced may actually worsen the entrepreneur's health conditions, causing a downward spiral of diminished health and decreased ability to address the competitive pressure of the venture's environment. The outcome of such a downward spiral for the entrepreneur may not only be decreased motivation for continuing the venture but also bad health. These and related research questions warrant considerable attention to clarify the relationship between entrepreneurs' health and motivation and thereby help those with physical or psychological health problems develop successful entrepreneurial careers.

Finally, motivation can also come from an individual's values. Building on Schwartz (1992; Holland and Shepherd 2013), we discussed the role of the following values in motivating entrepreneurial action: (1) selfenhancement, (2) openness to change, (3) self-transcendence, and (4) conservation. More precisely, we discussed the role of values and other motivational influences in the decision to persist with a particular course of action when the best decision is to stop the action-in this case, terminate the project or business. Entrepreneurs persist with a losing course of action because of (1) personal sunk costs, (2) personal self-interest, (3) lack of other personal opportunities, (4) norms for consistency, (5) previous organizational success, and (6) perceived collective efficacy of organizational members. The impact of these attributes on the decision to persist with a losing course of action depends on the entrepreneur's level of extrinsic motivation (DeTienne et al. 2008). Such persistence can be costly to the entrepreneur and stakeholders if and when the venture eventually fails (Shepherd et al. 2009a, b). Therefore, more motivation is not always an unambiguous blessing in the entrepreneurial context. We encourage further research on the conditions in which entrepreneurial motivation is good or bad for the individual and his or her venture and the ways entrepreneurs can balance both their motivation to start and develop a venture and their ability able to withdraw from the venture when feedback from the environment signals that future success is highly unlikely.

\section{Attention and Entrepreneurial Cognition}

In Chap. 4, we discussed the role of attention in the entrepreneurial process. We distinguished between top-down and bottom-up attention allocation and noted how we most often think about entrepreneurial decision making and action arising from a top-down approach. However, we highlighted how bottom-up processes can operate as individuals detect and interpret signals of 
potential opportunities (Shepherd et al. 2007, 2017). In this situation, the entrepreneur's attention is "free" to be drawn to changes in the external environment and can be focused on interpreting the nature of and the potential opportunities arising from these environmental changes. More research is needed on the role of bottom-up attention-allocation processes in the detection and interpretation of signals of environmental change and how these interpretations impact the formation of opportunity beliefs. We suspect that this future research on attention will involve consideration of entrepreneurs' task demands given that attention allocated to demanding tasks is simultaneously unavailable for scanning the external environment for signals of potential opportunities (i.e., people have limited attentional capacity).

Of course, attention may not be allocated to one task and one potential opportunity. In Chap. 4 , we also detailed how the composition of a portfolio of potential opportunities at varying stages of development reflects different firm capabilities for advancing or terminating potential opportunities at specific stages of development in a timely manner. These capabilities to speed opportunity advancement or terminate opportunity pursuit are reflected in the firm's experiences, standard operating procedures, and confidence-all of which direct attention within the organization. In the chapter findings, we also highlighted how engineers were disappointed when the marginal projects they were working on were not terminated-they wanted to be transferred to the next hot project. Indeed, although those who were immediately transferred from a failing project to a new project experienced positive emotions, they did not reflect on the failed project and therefore did not learn from the experience (and neither did the organization). In contrast, those who experienced a delayed termination felt negative emotions but used that time to reflect on, document, and ultimately learn from the failure experience (Shepherd et al. 2014). Future research can, for example, explore how the apparent conflict between experiencing negative emotions and learning can be resolved - that is, under what conditions can team members minimize negative emotions and maximize learning within the project-shutdown period? In addition, perhaps some managerial interventions and support practices can direct employees' attention toward learning in quickly terminated projects (yielding few negative emotions) or minimize the experience of negative emotions in slowly terminated projects (yielding opportunities for learning).

Finally, while much of individuals' attention is automatically allocated to stimuli to inform their decisions, this automaticity can create some problems, especially when thinking about novel tasks and/or working in novel environments. Metacognition is thinking about one's thinking, which 
enables a more conscious consideration of the current task (similarities and differences) vis-à-vis other decision situations that require one to choose among alternate decision strategies and monitor progress in exploiting that decision strategy. While we speculate that a metacognitive approach is likely to be most useful in novel contexts and when decision speed is not critical, empirical evidence is needed to explore this claim. For example, scholars may explore the potential benefits and downsides of metacognition for entrepreneurs acting in industries with varying degrees of dynamism and technological change.

\section{IDENTITy AND ENTREPRENEURIAL Cognition}

In Chap. 5, we discussed entrepreneurial identity. Identity has a number of important implications in the entrepreneurial context. We described how people who pursue an entrepreneurial career are able to satisfy their need for distinctiveness but also acknowledged that people have the need to belong and that satisfying such a need is both distinctive to and a challenge for entrepreneurs. Indeed, many entrepreneurs report feeling lonely. In Chap. 5, we also discussed how entrepreneurs can develop an identity with the optimal level of distinctiveness by combining their work identity with their non-work identity in a way that maximizes psychological well-being. Of course, we realize (partly from our own experiences) that it is not always easy to "manage" one's work and non-work identities because they conflict at times. Therefore, we discussed alternate identity-management strategies-compartmentalization and integration-and the conditions under which one is more likely to be successful than the other (see Shepherd and Haynie 2009). Going forward, research may explore how entrepreneurs successfully implement these strategies in their daily lives and what aspects of their work- and non-work-related identities they need to manage most actively to resolve identity conflict. Perhaps some industries (e.g., those that are highly competitive) make identity management more challenging than other industries, and perhaps entrepreneurs with some specific personalities are more successful in resolving identity conflict than other entrepreneurs. We believe that there is ample room for research to build on our arguments about entrepreneurs' identity-management strategies.

We also explained how identities are sometimes lost and how the pursuit of a potential opportunity and/or entrepreneurial career can help individuals find, develop, and refine a new work identity. In the case of identity loss from a traumatic event, the first step toward creating a new 
identity is to build an identity foundation. An identity foundation requires the individual to rebuild fundamental assumptions about the world, humanity, and the self. Without this foundation, identity work will likely fail. Importantly, these individuals (i.e., those who have lost their identity due to a traumatic event) can develop a motivation for an entrepreneurial career (through both pull and push motivations) and can think creatively about how their past career competencies apply to new possible entrepreneurial careers (Haynie and Shepherd 2011). At the same time, these insights open up various future research opportunities. For example, how does the nature of the traumatic event impact the individual's motivation to pursue an entrepreneurial career and the type of venture founded? Also, how does the type and strength of the identity lost by the traumatic event impact entrepreneurial motivation? Perhaps the individual's personality influences to what extent entrepreneurial motivation impacts his or her recovery from trauma through the pursuit of an entrepreneurial career. Understanding these boundary conditions of entrepreneurial motivation as a response to trauma is important not only for building a new theory of entrepreneurial motivation but also for helping traumatized individuals decide whether an entrepreneurial career is an appropriate way to move on in their lives.

We continued this discussion of creating a new identity by exploring the situation of people hitting rock bottom. Rock bottom provides a context for escape. While some escape through identity play, which provides a basis for exploring a range of potential careers and a pathway to recovery, there is a dark side. The dark side involves escape through cognitive deconstruction, which hinders any progress in creating a new identity and stalls recovery (or worse). Individuals who hit rock bottom after losing a career can be helped if they think about the boundary between fantasy and reality, immersed in the present, and engage identity play (Shepherd and Williams 2018). Again, we expect future research to provide valuable insights for both scholars and those who hit rock bottom by building on our work. For example, there are different antecedents and obstacles to engaging in identity play. For example, those who hit rock bottom have a different "psychological space" for identity play (see also Petriglieri and Petriglieri 2010). It would be interesting to study under what conditions entrepreneurs who hit rock bottom have more or less psychological space for identity play and when they are more likely to use this psychological space for identity play as a basis for recovery from hitting rock bottom. In addition, we know little about what tools help people recover with identity 
play (e.g., scenario planning (Brown and Starkey 2000)). Finally, those who hit rock bottom may create different types of positive identities during recovery. For example, how do different types of identity play as well as different ways of carrying out identity play create new (entrepreneurial) identities, such as those that are positive but may also represent downgrades in some respect (Newman 1988)? Also, what role does culture play in enabling or hindering successful recovery from hitting rock bottom as well as in engaging in identity play?

Furthermore, as discussed in the chapter, an entrepreneur can have multiple identities, and these identities can come into conflict. Such identity conflict is particularly salient in the family business context. Indeed, we discussed the conflict between the family identity and the owner identity in family businesses and the ways this identity conflict can slow entrepreneurial decision making. We also offered some suggestions for how to manage potential identity conflict to speed entrepreneurial decision making. However, we also note here that the nature of both the family and the family business may influence the generation of and escape from identity conflict. These issues warrant further research. For instance, families differ in the extent to which they are involved in the family business. As such, does the conflict between a person's owner and family identities evolve differently if more members of a family are involved in the business? How does conflict among family members (either involved in the business or not) influence the identity conflict that emerges? Further, is this conflict resolved more or less easily (or resolved in a different manner) when the family business has existed for more generations or when it is run by an outside CEO rather than a family CEO? How do non-economic goals often pursued by family members (Chrisman et al. 2014) influence their identity conflict? Future research can make important contributions by exploring these and other questions regarding the family- and businessrelated factors behind the emergence and resolution of identity conflict for family owner-managers.

\section{EMOTION AND ENTREPRENEURIAL COGNITION}

In Chap. 6, we discussed the role of emotion in entrepreneurship. We highlighted that an entrepreneurial career can generate both high positive emotions and high negative emotions. First, we described passion and distinguished between harmonious and obsessive passion and how they influence the decision to exploit a new potential opportunity. We also 
explained how another positive emotion-excitement-moderates the relationship between passion and the decision to exploit a potential opportunity. However, here, we also note that passion and excitement are only two out of many positive emotions that might play a role in entrepreneurial decision making. For example, Welpe et al. (2012) found that joy can increase the positive impact of opportunity evaluation on exploitation, and Baron (2008) argued that positive emotions generally facilitate opportunity recognition. Therefore, there is good reason to believe that additional positive emotions, such as enthusiasm, happiness, pride, or boldness, might play an important role in opportunity recognition and exploitation. Further, in addition to experiencing these emotions, anticipating such emotions might influence the entrepreneurial process. For example, entrepreneurs who anticipate pride about successfully founding a venture might be more driven toward opportunity recognition and exploitation than those who tend to experience little pride in general. Moreover, a few studies have addressed the issue of negative emotions in the entrepreneurial process. These studies have shown, for example, that entrepreneurs tend to experience fewer negative emotions than non-entrepreneurs (Patzelt and Shepherd 2011), but they have also highlighted the important role of specific negative emotions (e.g., fear and anger) (Welpe et al. 2012; Mitchell and Shepherd 2010) for opportunity evaluation and exploitation. We expect that the study of positive and negative emotions' role in the entrepreneurial process will receive significant scholarly attention in the future.

Second, given that emotions play a key role in an individual's entrepreneurial cognition, we explained how managers' displays of emotions can influence employees' willingness to act entrepreneurially. Specifically, we highlighted our study with a colleague (Brundin et al. 2008) focusing on mangers' confidence, positive emotion of satisfaction, and negative emotions of frustration, worry, bewilderment, and strain and their impact on employees' willingness to act entrepreneurially; employees evaluated all these emotions as being influential for their entrepreneurial motivation. In addition, my (Holger) work with my colleagues (Breugst et al. 2012) found that employees' perceptions of entrepreneurial passion influence their commitment to new ventures but differently for different types of passion: while passion for innovation and venture development increases commitment, passion for founding has a negative effect. These studies reveal considerable potential for contribution when scholars explore not only entrepreneurs' emotions but also how individuals in their environment react to entrepreneurs' emotional displays. Indeed, the literature is almost silent on how 
employees perceive their work environment within startups, including entrepreneurs' emotional expressions. Further, there is initial evidence that entrepreneurs' passionate displays can trigger investors' funding decisions (Chen et al. 2009), which indicates that a variety of stakeholders (in addition to employees and investors including customers, suppliers, alliance partners) might be influenced by entrepreneurs' emotional displays. Scholars have plenty of opportunities to investigate how entrepreneurs' emotions and emotional displays influence their social environments and thereby ventures' access to resources and-ultimately-success.

We also detailed how employees often become attached to their projects and experience a negative emotional reaction-grief (Shepherd 2003) — when their projects (Shepherd et al. 2009a, 2011) or businesses fail (Byrne and Shepherd 2015; Shepherd 2003, 2009). These entrepreneurs often feel grief because they have lost something important to them-something that satisfied their needs for competence, autonomy, and belonging (Shepherd and Cardon 2009). These negative emotions can obstruct individuals' ability to learn from failure experiences and move on (Shepherd 2003; Shepherd et al. 2011). At the individual level, entrepreneurs (corporate or independent) can oscillate between a loss orientation and a restoration orientation as a means of "managing" negative emotions, which is superior to simply normalizing failure (i.e., taking emotion out of the entrepreneurial process altogether). These individuals can also show themselves self-compassion-self-kindness, common humanity, and mindfulness-which helps stop the escalation of negative emotions and facilitates learning from the experience. We also discussed implications of managing grief over project failure at the organizational level. As such, our work raises interesting questions that future research can explore. For example, how do organizational environment, culture, and leadership facilitate the oscillation between loss and restoration orientations? Further, how do different individuals achieve the best "balance" between these orientations based on their personality characteristics and the nature of their failure experience? We hope that we inspired research along these lines by summarizing what we know about the role of negative emotions in the context of entrepreneurial failure.

\section{Conclusion}

In conclusion, entrepreneurial cognition is a fascinating topic that has triggered our curiosity and inspired our research for more than a decade. While scholars have made considerable progress on studying this topic, 
this final chapter has shown that every research question addressed thus far has opened up more questions that are just as fascinating. The goal of this book was to both summarize what our work has contributed to current knowledge and identify the opportunities for research it has opened up for future scholarship. We hope you enjoyed our book and were able to glean some new insights into entrepreneurial cognition. Even more, we hope we triggered your motivation to join us on the exciting road ahead.

\section{REFERENCES}

Audretsch, D. B., \& Feldman, M. P. (1996). R\&D spillovers and the geography of innovation and production. American Economic Review, 86(3), 630-640.

Baron, R. A. (2006). Opportunity recognition as pattern recognition: How entrepreneurs "connect the dots" to identify new business opportunities. Academy of Management Perspectives, 20(1), 104-119.

Baron, R. A. (2008). The role of affect in the entrepreneurial process. Academy of Management Review, 33, 328-340.

Baron, R. A., \& Ensley, M. D. (2006). Opportunity recognition as the detection of meaningful patterns: Evidence from comparisons of novice and experienced entrepreneurs. Management Science, 52(9), 1331-1344.

Breugst, N., Domurath, A., Patzelt, H., \& Klaukien, A. (2012). Perceptions of entrepreneurial passion and employees' commitment to entrepreneurial ventures. Entrepreneurship Theory and Practice, 36, 171-192.

Brown, A. D., \& Starkey, K. (2000). Organizational identity and learning: A psychodynamic perspective. Academy of Management Review, 25(1), 102-120.

Brundin, E., Patzelt, H., \& Shepherd, D. A. (2008). Managers' emotional displays and employees' willingness to act entrepreneurially. Journal of Business Venturing, 23(2), 221-243.

Byrne, O., \& Shepherd, D. A. (2015). Different strokes for different folks: Entrepreneurial narratives of emotion, cognition, and making sense of business failure. Entrepreneurship Theory and Practice, 39, 375-405.

Cardon, M. S., Wincent, J., Singh, J., \& Drnovsek, M. (2009). The nature and experience of entrepreneurial passion. Academy of Management Review, 34(3), 511-532.

Chen, X. P., Yao, X., \& Kotha, S. (2009). Entrepreneur passion and preparedness in business plan presentations: A persuasion analysis of venture capitalists' funding decisions. Academy of Management Journal, 52, 199-214.

Chrisman, J. J., Memili, E., \& Misra, K. (2014). Nonfamily managers, family firms, and the winner's curse: The influence of noneconomic goals and bounded rationality. Entrepreneurship Theory and Practice, 38(5), 1103-1127.

Cohen, W. M., \& Levinthal, D. A. (1990). Absorptive capacity: A new perspective on learning and innovation. Administrative Science Quarterly, 35(1), 128-152. 
Conroy, D. E. (2001). Progress in the development of a multidimensional measure of fear of failure: The performance failure appraisal inventory (PFAI). Anxiety, Stress and Coping, 14(4), 431-452.

Conroy, D. E., \& Elliot, A. J. (2004). Fear of failure and achievement goals in sport: Addressing the issue of the chicken and the egg. Anxiety, Stress and Coping, 17, 271-285.

Conroy, D. E., Willow, J. P., \& Metzler, J. N. (2002). Multidimensional fear of failure measurement: The performance failure appraisal inventory. Journal of Applied Sport Psychology, 14(2), 76-90.

Csikszentmihalyi, M. (1975). Play and intrinsic rewards. Journal of Humanistic Psychology, 15(3), 41-63.

Csikszentmihalyi, M. (2000). Beyond boredom and anxiety. San Francisco: Jossey-Bass.

DeTienne, D. R., Shepherd, D. A., \& De Castro, J. O. (2008). The fallacy of "only the strong survive": The effects of extrinsic motivation on the persistence decisions for underperforming firms. Journal of Business Venturing, 23(5), $528-546$.

Domurath, A., \& Patzelt, H. (2016). Entrepreneurs' assessments of early international entry: The role of foreign social ties, venture absorptive capacity, and generalized trust in others. Entrepreneurship Theory and Practice, 40(5), 1149-1177.

Dutton, J. E. (1993). Interpretations on automatic: A different view of strategic issue diagnosis. Journal of Management Studies, 30(3), 339-357.

Fiet, J. O. (1996). The informational basis of entrepreneurial discovery. Small Business Economics, 8(6), 419-430.

Hart, S. L. (2006). Worlds in collision. Global Business and Organizational Excellence, 25(3), 13-25.

Haynie, J. M., \& Shepherd, D. (2011). Toward a theory of discontinuous career transition: Investigating career transitions necessitated by traumatic life events. Journal of Applied Psychology, 96(3), 501.

Holland, D. V., \& Shepherd, D. A. (2013). Deciding to persist: Adversity, values, and entrepreneurs' decision policies. Entrepreneurship Theory and Practice, $37(2), 331-358$.

Julian, S. D., Ofori-Dankwa, J. C., \& Justis, R. T. (2008). Understanding strategic responses to interest group pressures. Strategic Management Journal, 29(9), 963-984.

Maheswaran, D., \& Sternthal, B. (1990). The effects of knowledge, motivation, and type of message on ad processing and product judgments. Journal of Consumer Research, 17(1), 66-73.

McMullen, J. S., \& Shepherd, D. A. (2006). Entrepreneurial action and the role of uncertainty in the theory of the entrepreneur. Academy of Management Review, 31(1), 132-152. 
Mitchell, J. R., \& Shepherd, D. A. (2010). To thine own self be true: Images of self, images of opportunity, and entrepreneurial action. Journal of Business Venturing, 25, 138-154.

Newman, K. S. (1988). Falling from grace: The experience of downward mobility in the American middle class. New York: Free Press.

Patzelt, H., \& Shepherd, D. A. (2011). Recognizing opportunities for sustainable development. Entrepreneurship Theory and Practice, 35(4), 631-652.

Petriglieri, G., \& Petriglieri, J. L. (2010). Identity workspaces: The case of business schools. Academy of Management Learning of Education, 9(1), 44-60.

Schwartz, S. H. (1992). Universals in the content and structure of values: Theoretical advances and empirical tests in 20 countries. Advances in Experimental Social Psychology, 25, 1-65.

Shah, S. K., \& Tripsas, M. (2007). The accidental entrepreneur: The emergent and collective process of user entrepreneurship. Strategic Entrepreneurship Journal, 1(1-2), 123-140.

Shane, S. (2000). Prior knowledge and the discovery of entrepreneurial opportunities. Organization Science, 11(4), 448-469.

Shepherd, D. A. (2003). Learning from business failure: Propositions of grief recovery for the self-employed. Academy of Management Review, 28, 318-328.

Shepherd, D. A. (2009). Grief recovery from the loss of a family business: A multiand meso-level theory. Journal of Business Venturing, 24(1), 81-97.

Shepherd, D. A., \& Cardon, M. S. (2009). Negative emotional reactions to project failure and the self-compassion to learn from the experience. Journal of Management Studies, 46(6), 923-949.

Shepherd, D. A., \& DeTienne, D. R. (2005). Prior knowledge, potential financial reward, and opportunity identification. Entrepreneurship Theory and Practice, $29(1), 91-112$.

Shepherd, D., \& Haynie, J. M. (2009). Birds of a feather don't always flock together: Identity management in entrepreneurship. Journal of Business Venturing, 24(4), 316-337.

Shepherd, D. A., \& Patzelt, H. (2011). The new field of sustainable entrepreneurship: Studying entrepreneurial action linking "what is to be sustained" with "what is to be developed". Entrepreneurship Theory and Practice, 35(1), 137-163.

Shepherd, D. A., \& Patzelt, H. (2015). Harsh evaluations of entrepreneurs who fail: The role of sexual orientation, use of environmentally friendly technologies, and observers' perspective taking. Journal of Management Studies, 52, 253-284.

Shepherd, D., \& Williams, T. (2018). Hitting rock bottom after job loss: Bouncing back to create a new positive work identity. Academy of Management Review, amr-2015.

Shepherd, D. A., McMullen, J. S., \& Jennings, P. D. (2007). The formation of opportunity beliefs: Overcoming ignorance and reducing doubt. Strategic Entrepreneurship Journal, 1(1-2), 75-95. 
Shepherd, D. A., Covin, J. G., \& Kuratko, D. F. (2009a). Project failure from corporate entrepreneurship: Managing the grief process. Journal of Business Venturing, 24(6), 588-600.

Shepherd, D. A., Wiklund, J., \& Haynie, J. M. (2009b). Moving forward: Balancing the financial and emotional costs of business failure. Journal of Business Venturing, 24(2), 134-148.

Shepherd, D. A., Patzelt, H., \& Wolfe, M. (2011). Moving forward from project failure: Negative emotions, affective commitment, and learning from the experience. Academy of Management Journal, 54, 1229-1259.

Shepherd, D. A., Patzelt, H., Williams, T. A., \& Warnecke, D. (2014). How does project termination impact project team members? Rapid termination, 'creeping death', and learning from failure. Journal of Management Studies, 51(4), 513-546.

Shepherd, D. A., McMullen, J. S., \& Ocasio, W. (2017). Is that an opportunity? An attention model of top managers' opportunity beliefs for strategic action. Strategic Management Journal, 38(3), 626-644.

Welpe, I. M., Spörrle, M., Grichnik, D., Michl, T., \& Audretsch, D. B. (2012). Emotions and opportunities: The interplay of opportunity evaluation, fear, joy, and anger as antecedent of entrepreneurial exploitation. Entrepreneurship Theory and Practice, 36(1), 69-96.

Wiklund, J., Patzelt, H., \& Dimov, D. (2016). Entrepreneurship and psychological disorders: How ADHD can be productively harnessed. Journal of Business Venturing Insights, 6, 14-20.

Zahra, S. A., \& George, G. (2002). Absorptive capacity: A review, reconceptualization, and extension. Academy of Management Review, 27(2), 185-203.

Open Access This chapter is licensed under the terms of the Creative Commons Attribution 4.0 International License (http://creativecommons.org/licenses/ by $/ 4.0 /)$, which permits use, sharing, adaptation, distribution and reproduction in any medium or format, as long as you give appropriate credit to the original author(s) and the source, provide a link to the Creative Commons license and indicate if changes were made.

The images or other third party material in this chapter are included in the chapter's Creative Commons license, unless indicated otherwise in a credit line to the material. If material is not included in the chapter's Creative Commons license and your intended use is not permitted by statutory regulation or exceeds the permitted use, you will need to obtain permission directly from the copyright holder.

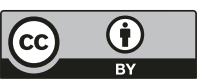

